\title{
TRADUÇÃO
}

\section{A busca da verdade pela luz natural ${ }^{1}$ \\ (parte 2) \\ RENÉ DESCARTES}

Tradução de Caroline de Paula Bueno, Felipe Belin, Gustavo Henrique Martins, Leonan Ferrari Felipin, Suellen Dantas Godoi, Vanessa Henning

Organização e Revisão de César Augusto Battisti²

\section{Nota Introdutória}

César Augusto Battisti

Em continuidade à tradução da primeira parte da obra de René Descartes (1596-1650) intitulada "La Recherche de la Vérité par la Lumière Naturelle” (“A Busca da Verdade pela Luz Natural"), publicada no número imediatamente anterior desta mesma Revista, oferecemos ao público-leitor em língua portuguesa a tradução da sua segunda parte. Para facilitar o acesso ao número anterior da revista, segue o link: http://e-revista.unioeste.br/index.php/diaphonia/issue/view/988.

O trabalho de tradução foi realizado por membros do Grupo PET-Filosofia da Unioeste, durante os anos de 2016 e 2017, sob minha supervisão e revisão.

Maiores informações sobre a tradução e a obra se encontram na Nota Introdutória à primeira parte.

\section{A Busca da Verdade pela Luz Natural (parte 2)}

EUDOXO - Vós estais muito bem preparado, e é precisamente por aí que eu gostaria de vos conduzir. Mas, agora, é o momento em que é preciso que presteis atenção às consequências que quero tirar dessas premissas. Vedes, então, que podeis duvidar, com razão, de todas as coisas cujo conhecimento vos ocorre apenas com a ajuda dos sentidos; mas podeis duvidar de vossa dúvida e permanecer incerto de que duvidais ou não?

POLIANDRO - Confesso que isso me enche de espanto, e o pouco de perspicácia que devo ao meu frágil bom senso faz que eu, com assombro, me veja forçado a reconhecer que nada faço com alguma certeza, que duvido de tudo e que não estou certo de nada. O que, porém, quereis concluir a partir daí? Não vejo para que possa

\footnotetext{
${ }^{1} \mathrm{O}$ texto original, em francês, intitulado La Recherche de la Vérité par la Lumière Naturelle, está na edição standard das Eruvres de Descartes, em seu volume X, p. 495-527, a primeira parte, em francês, se estendendo da p. 495 até a p. 514, e a segunda parte, em latim, da p. 514 até a p. 527.

${ }^{2}$ Professor dos Cursos de Graduação e Pós-Graduação Stricto Sensuem Filosofia da UNIOESTE. ExTutor do PET-Filosofia da UNIOESTE (2006-2010). Endereço eletrônico: cesar.battisti@hotmail.com
} 
servir esse espanto universal nem como uma tal dúvida possa ser um princípio capaz de nos conduzir tão longe. Ao contrário, o objetivo que haveis dado a este diálogo é o de livrarmo-nos de nossas dúvidas e o de nos fazer conhecer verdades que poderiam ser ignoradas por Epistemon, por mais sábio que ele seja.

EUDOXE - Emprestai-me apenas vossa atenção, e eu vos conduzirei mais longe do que pensais. Pois, a partir dessa dúvida universal, como de um ponto fixo e imóvel, quero derivar o conhecimento de Deus, o de vós mesmo e, finalmente, o de todas as coisas que existem na natureza.

POLIANDRO - Eis aqui, certamente, grandes promessas, e, desde que sejam cumpridas, elas valem que nós vos concedamos o objeto de vosso pedido. Sede, portanto, fiel às vossas promessas, e nós cumpriremos as nossas.

EUDOXE - E, então, como não podeis negar que duvidais, e, ao contrário, é certo que duvidais e, mesmo, tão certo que não podeis duvidar disso, também é verdade que vós que duvidais existis, e isso é tão verdadeiro que disso não podeis duvidar mais.

POLIANDRO - Eu sou da vossa opinião; pois, se eu não existisse, eu não poderia duvidar.

EUDOXE - Vós existis, portanto, e sabeis que existis, e vós o sabeis porque duvidais.

POLIANDRO - Tudo isso é verdadeiro.

EUDOXE - Então, para que não sejais desviado do vosso propósito, avancemos aos poucos, e, como vos disse, descobrireis que esta estrada vai mais longe do que pensais. Repitamos o argumento: vós existis, sabeis que existis e o sabeis porque sabeis que duvidais. Mas, vós, que duvidais de tudo e que não podeis duvidar de vós mesmo, quem sois vós?

POLIANDRO - A resposta não é difícil, e eu pressinto por que me escolhestes como interlocutor preferencialmente a Epistemon: é que não quereis pôr nenhuma questão que não seja muito fácil de responder. Direi, portanto, que sou um homem.

EUDOXE - Vós não prestais atenção ao que vos peço, e a resposta que me apresentais, por mais simples que ela vos possa parecer, vos lançaria para questões muito difíceis e muito confusas, caso eu quisesse, por pouco que fosse pressioná-lo. De fato, se eu perguntasse a Epistemon, por exemplo, o que é um homem, e ele respondesse, como nas escolas, que um homem é um animal racional, e se, além disso, para explicar esses dois termos, que não são menos obscuros do que o primeiro, ele nos conduzisse por todos os graus que chamamos metafísicos, certamente teríamos penetrado em um labirinto do qual jamais poderíamos sair. Pois, dessa questão nascem outras duas: a primeira, o que é um animal? e a segunda, o que é ser racional? E, se, além disso, para explicar o que é um animal, ele 
respondesse que é um ser vivo e sensível, que um ser vivo é um corpo animado e que um corpo é uma substância corpórea, podeis notar imediatamente que as questões iriam aumentar e se multiplicar como os ramos de uma árvore genealógica, e é bem evidente que todas essas belas questões terminariam em uma pura redundância que não esclareceria nada e nos deixaria em nossa ignorância primeira.

EPISTEMON - É com grande pesar que vos vejo desprezar tão fortemente essa árvore de Porfírio que sempre esteve sob a admiração de todos os sábios, e, além disso, estou incomodado com vossa tentativa de ensinar a Poliandro o que ela é por um outro método que não aquele que há tanto tempo é aceito em todas as escolas. Com efeito, não foi possível encontrar até nossos dias um método melhor para nos ensinar o que somos senão este que coloca sucessivamente diante de nossos olhos todos os graus que constituem o conjunto de nosso ser, a fim de que, subindo e descendo por todos esses graus, possamos aprender o que temos em comum com os outros seres e o que nos diferencia deles; e esse é o ponto mais alto que a inteligência humana pode atingir.

EUDOXO - Nunca me coloquei nem me colocarei na posição de censurar o método de ensino empregado nas escolas; pois é a ele que devo o pouco que sei e é dos recursos por ele fornecidos que eu me servi para reconhecer a incerteza de tudo o que lá aprendi. Além disso, por mais que meus preceptores jamais tenham me ensinado algo de certo, ainda assim lhes devo agradecer por ter aprendido com eles a reconhecê-lo, e tenho mais obrigação com eles pelo fato de que todas as coisas que me ensinaram são duvidosas antes do que se elas estivessem mais conformes à razão; pois, nesse caso, talvez eu tivesse me contentado com o pouco de razão que eu teria aí descoberto, e isso teria me tornado menos entusiasmado para procurar com mais cuidado a verdade. Assim, portanto, a advertência que fiz a Poliandro serve menos para que ele observe a incerteza e a obscuridade para as quais a resposta dele vos encaminha do que para torná-lo, no futuro, ele mesmo mais atento às minhas questões. Isto posto, retorno ao meu projeto; e, para não mais nos afastarmos dele, pergunto a ele novamente o que ele é, ele que pode duvidar de tudo e que não pode duvidar de si mesmo.

POLIANDRO - Eu acreditava já vos haver satisfeito a esse respeito ao dizer que eu era um homem; mas reconheço agora que minha resposta não fora bem sopesada, pois vejo que ela não vos agrada; e, para falar francamente, neste momento é a mim que ela não parece mais suficiente, sobretudo quando considero que vós me haveis mostrado os embaraços e as incertezas em que ela poderia nos jogar, se quisermos esclarecê-la e entendê-la. De fato, independentemente do que diga Epistemon, eu encontro muita obscuridade nesses graus metafísicos. Se alguém disser, por exemplo, que um corpo é uma substância corpórea sem, ao mesmo tempo, definir o que é uma substância corpórea, estas duas palavras, substância corpórea, não nos fazem, de maneira alguma, mais sábios que a palavra corpo. Da mesma forma, se 
alguém afirma que um ser vivo é um corpo animado sem ter previamente explicado o significado das palavras corpo e animado, e não é diferente para todos os outros graus metafísicos, certamente pronuncia palavras, e até mesmo palavras dispostas em uma certa ordem, mas não diz nada; pois isso não significa nada que possa ser concebido e formar, em nossa mente, uma ideia clara e distinta. Há mais: quando, para satisfazer a esta questão, respondi que eu era um homem, não pensei em todos esses seres escolares que me eram desconhecidos e dos quais eu jamais havia ouvido falar coisa alguma, os quais, penso eu, não existem senão na imaginação daqueles que os inventaram; mas eu gostaria de falar das coisas que vemos e tocamos, que sentimos e experimentamos em nós mesmos, em uma palavra, das coisas de que o mais simples dos homens sabe tanto quanto o maior filósofo do universo; eu queria, enfim, dizer que eu sou um certo todo composto por dois braços, duas pernas, de uma cabeça e de todas as outras partes que constituem o que se chama corpo humano, cujo todo, além disso, se nutre, anda, senta e pensa.

EUDOXO - Já conclui de vossa resposta que não haveis bem compreendido minha questão, e que respondeis com mais coisas do que as que eu vos perguntei; mas, como haveis já colocado, entre o número de coisas das quais duvidais, os braços, as pernas, a cabeça e todas as outras partes que compõem a máquina do corpo humano, eu não quis, de modo algum, vos interrogar sobre todas essas coisas cuja existência não vos parece certa. Dizei-me, então, o que sois propriamente enquanto duvidais. Com efeito, é aqui que está o único ponto, visto que não podeis conhecer nenhum outro com certeza, sobre o qual eu gostaria de vos interrogar.

POLIANDRO - Vejo agora, certamente, que eu me enganei em minha resposta, e que fui mais longe do que deveria, porque eu não havia capturado suficientemente bem vosso pensamento. Isso me tornará também mais circunspecto no futuro, e me leva, ao mesmo tempo, a admirar a precisão do vosso método, por meio do qual nos conduzis passo a passo, por vias simples e fáceis, ao conhecimento das coisas que quereis nos ensinar. E, no entanto, temos algum motivo para considerar proveitoso o erro que cometi, já que é a ele que devo agora por saber que o que sou, na medida em que duvido, não é de modo algum o que chamo de meu corpo. Ademais, nem mesmo sei se tenho um corpo, já que me mostrastes que posso duvidar disso. Acrescento também que tampouco posso negar em absoluto que eu tenha um corpo; no entanto, embora deixemos intactas todas essas suposições, isso não impedirá que eu esteja certo de minha existência; pelo contrário, elas me firmam ainda mais na certeza de que existo e que não sou um corpo. Pois, caso contrário, se eu duvidasse do meu corpo, eu duvidaria também de mim mesmo, o que me é impossível; pois estou plenamente convencido de que existo, e convencido de tal modo que não posso de modo algum duvidar disso.

EUDOXO - Vós falais maravilhosamente, e tratais tão bem da questão que nos ocupa que eu mesmo não poderia dizer melhor. Vejo que não é mais necessário 
senão vos confiar inteiramente a vós mesmos, depois de vos haver conduzido ao longo do caminho. Além disso, para descobrir as verdades até as mais difíceis, penso que seja suficiente o que se denomina vulgarmente senso comum, desde que ele, contudo, seja bem conduzido; e, como vos considero provido dele tanto quanto eu desejava, me contentarei, no futuro, em vos mostrar o caminho no qual deveis entrar. Continuai, portanto, a deduzir por vós mesmo as consequências desse primeiro princípio.

POLIANDRO - Este princípio me parece tão fecundo, e tantas coisas se oferecem ao mesmo tempo a mim, que terei, creio eu, bastante trabalho para colocá-las em ordem. Essa advertência que me destes, a de examinar o que sou, eu que duvido, e não confundir o que eu era com o que outrora acreditava ser, lançou tantas luzes em meu espírito e dele expulsou, desde o início, tão bem a escuridão que, com a luz desta tocha, vejo melhor em mim o que nela não se vê, e que eu jamais acreditei tão firmemente possuir um corpo tanto quanto agora acredito possuir o que não se pode tocar.

EUDOXO - Esse fervor agrada-me muito, por mais que talvez desagrade a Epistemon, que, enquanto não o tereis arrancado de seu erro e não lhe tereis colocado diante dos olhos uma parte das coisas que dizeis estarem contidas neste princípio, sempre terá um pretexto para acreditar, ou pelo menos para temer, que essa luz que vos é oferecida seja semelhante àqueles fogos errantes que se apagam e desaparecem tão logo nos aproximamos, e que, a partir de então, não recaiais imediatamente em vossa escuridão inicial, isto é, em vossa antiga ignorância. E, certamente, seria uma maravilha se vós, não havendo estudado e não havendo lido as obras dos filósofos, vos tornásseis sábio tão rapidamente e com tão pouca dificuldade. Não é de se surpreender, portanto, se Epistemon vos julgar assim.

EPISTEMON - Confesso que tomei isso por um momento de entusiasmo, e pensei que Poliandro, que jamais se aplicou a conhecer as grandes verdades que a filosofia ensina, tenha sido atingido por uma tal alegria ao examinar a menor dentre elas que não pôde se impedir de o testemunhar por uma tal manifestação. Aqueles, porém, que, como vós, andaram por muito tempo nesta estrada e gastaram muito óleo e esforço para ler e reler os escritos dos antigos, para desemaranhar e explicar o que há de mais espinhoso nos filósofos, não se espantam mais com esses momentos de entusiasmo e não os consideram mais do que vã esperança à qual se agarram alguns daqueles que nada mais fizeram até agora senão render homenagem à antessala dos matemáticos. Estes, com efeito, tão logo lhes haveis dado uma linha e um círculo e ensinado o que é uma linha reta e uma linha curva, se persuadem que irão encontrar a quadratura do círculo e a duplicação do cubo. Ocorre que nós refutamos tantas vezes a doutrina dos pirrônicos, e eles retiraram, eles mesmos, tão poucos frutos de seu método de filosofar que vagaram por toda a vida e não conseguiram se livrar das dúvidas que introduziram na filosofia, de modo que aparentam ter dirigido suas 
ações apenas para ensinar a duvidar. E, também, espero que isso não desagrade a Poliandro, mas duvido que ele possa, ele mesmo, retirar daqui algo melhor.

EUDOXO - Bem vejo que, ao dirigirdes a palavra a Poliandro, quereis poupar-me; todavia, é manifesto que sou o objetivo de vossa ironia. Mesmo assim, que Poliandro continue a falar; veremos em seguida quem de nós rirá por último.

POLIANDRO - Farei com prazer, tanto mais que é de se temer que este debate se aqueça entre vós, e que, caso renomeais a coisa de muito alto, eu não compreenderei mais nada: ver-me-ia, então, privado dos frutos que prometi a mim mesmo colher ao retomar meus primeiros estudos. Peço, portanto, Epistemon, que me permita nutrir esta esperança pelo tempo que agradará a Eudoxo me guiar pela mão no caminho em que ele mesmo me colocou.

EUDOXO - Já bem reconhecestes, em vos considerardes apenas enquanto duvidais, que não éreis um corpo e, portanto, que não encontrareis em vós nenhuma das partes que constituem a máquina do corpo humano, isto é, nem braços, nem pernas, nem cabeça, nem olhos, nem ouvidos ou órgão algum que possa ser útil a qualquer um dos sentidos; mas vede se, da mesma maneira, não possais rejeitar todas as outras coisas que haveis incluído há pouco na definição de homem, tal como o concebíeis anteriormente. Pois, como dissestes com razão, foi um erro afortunado aquele que cometestes excedendo em vossa resposta os limites da minha questão; com auxílio dele, com efeito, podeis chegar ao conhecimento do que sois, afastando de vós e rejeitando tudo o que vedes claramente não vos pertencer, e nada admitindo que não vos pertença de tal modo necessariamente quanto estais tão seguro tanto de vossa existência como de vossa dúvida.

POLIANDRO - Agradeço-vos por me trazer de volta ao meu caminho, pois já não sabia onde estava. Eu afirmei pouco antes que eu era um todo formado de dois braços, de duas pernas, de uma cabeça, enfim, de todas as outras partes que compõem o que se chama de corpo humano; ademais, era um todo que andava, se alimentava, sentia e pensava. Foi preciso também, para me considerar simplesmente tal como sei ser, rejeitar todas essas partes ou todos esses membros que constituem a máquina do corpo humano, ou seja, me considerar sem braços, sem pernas, sem cabeça, em uma palavra, sem corpo. Ora, é verdade que aquele que duvida em mim não é o que dizemos ser nosso corpo; é, pois, também verdade que eu, enquanto duvido, não me alimento, não ando, pois nem um nem outro desses dois atos pode ser feito sem o corpo. Bem mais, não posso nem mesmo afirmar que eu, enquanto duvido, possa sentir. Pois, da mesma forma que os pés são necessários para caminhar, assim também os olhos o são para ver e os ouvidos para escutar, mas, como não tenho nenhum desses órgãos, visto que não tenho corpo, não posso afirmar que sinto. Além disso, acreditei antigamente sentir em sonhos muitas coisas que, no entanto, realmente não sentia; e, uma vez que resolvi nada admitir aqui que não seja de tal modo verdadeiro que dele eu não possa duvidar, não posso dizer que 
sou uma coisa que sente, isto é, uma coisa que vê pelos olhos e escuta pelas orelhas; pois poderia acontecer que eu acreditasse sentir desta maneira, embora nenhum desses atos tivesse ocorrido.

EUDOXO - Não posso me impedir de vos interromper aqui, não para vos desviar de vossa jornada, mas para vos encorajar e vos fazer examinar o que pode o bom senso bem governar. Com efeito, em tudo o que acabais de dizer, não há nada que não seja exato, nada que não esteja legitimamente concluído e rigorosamente deduzido. E, entretanto, todas essas consequências são feitas sem lógica, sem uma fórmula de argumentação, mas com a ajuda só das luzes da razão e do bom senso, que se encontra menos sujeito a se enganar quando age sozinho e por si mesmo do que quando procura com inquietação observar mil regras diferentes, que a arte e a preguiça dos homens inventaram para corrompê-lo mais do que para aperfeiçoá-lo. O próprio Epistemon parece aqui partilhar a nossa opinião, pois seu silêncio dá a entender que ele aprova o que vós dissestes. Continuai, então, Poliandro, e mostrailhe até aonde o bom senso pode ir, e ao mesmo tempo as consequências que podem ser deduzidas de nossos princípios.

POLIANDRO - De todos os atributos que me atribui, resta apenas um para examinar, o pensamento, e considero que ele é, só ele, de uma natureza tal que não posso separá-lo de mim; pois, se é verdade que duvido e como disso não posso duvidar, é igualmente verdadeiro que penso. O que é, com efeito, duvidar senão pensar de uma certa maneira? E, com certeza, se eu não pensasse, não poderia saber se duvido nem se existo. Eu existo, contudo, e sei que existo, e o sei porque duvido, isto é, porque penso; e, mesmo, poderia acontecer que, se, por um momento, eu cessasse de pensar, eu cessaria ao mesmo tempo de existir. E, portanto, a única coisa que não consigo separar de mim, que eu sei com certeza ser eu e que posso agora afirmar, sem medo de me enganar, é que sou um ser pensante.

EUDOXO - O que vos parece, Epistemon, do que Poliandro acabou de dizer? Considerais em todo o seu raciocínio algo defeituoso ou que não seja consequente? Acreditaríeis que um iletrado e sem estudos raciocinasse de modo tão justo e fosse em tudo consequente consigo mesmo? Desta forma, pois, se eu julgo bem, vós deveis começar a ver que, desde que saibamos nos servir convenientemente da dúvida, podemos daí deduzir conhecimentos muito certos, e mesmo mais certos e mais úteis do que todos aqueles que ordinariamente são tirados daquele grande princípio que tomamos por base de todos os conhecimentos e como centro ao qual todos eles são reconduzidos e no qual terminam: é impossível que, no mesmo instante, uma só e mesma coisa seja e não seja mais. Talvez eu tenha oportunidade de vos mostrar a utilidade disso; mas, para não cortar o fio do discurso de Poliandro, não nos afastemos do nosso assunto, e interrogai vós mesmo para saber se não tendes nada a dizer ou a objetar. 
EPISTEMON - Já que me tomais como parte acusada, e mesmo tendo sido por vós atacado, vou mostrar o que a lógica vos pode desagradar e, ao mesmo tempo, vos criar tantos embaraços e obstáculos que, não somente Poliandro, mas vós mesmo dificilmente podereis vos safar. Não iremos, portanto, mais longe, mas antes detenhamo-nos aqui, e examinemos severamente os princípios que vos servem de base, e vossas consequências. Pois, com o auxílio da verdadeira lógica, e por meios de vossos princípios neles mesmos, eu vos demonstrarei que tudo o que disse Poliandro não repousa sobre um fundamento legítimo e nada conclui. Vós dizeis que existis, que sabeis que existis, e que disso sabeis porque duvidais e porque pensais. Mas o que é duvidar, o que é pensar, vós o sabeis? E, visto não quereis nada admitir do qual não estejais certo e não conheçais perfeitamente, como podeis estar certo de que existis apoiando-vos em fundamentos tão obscuros e, consequentemente, tão pouco certos? Seria preciso, primeiramente, que ensinásseis a Poliandro o que é a dúvida, o pensamento, a existência, a fim de que seu raciocínio pudesse ter a força de uma demonstração, e que ele mesmo pudesse compreenderse antes de querer se fazer compreender aos outros.

POLIANDRO - Eis algo que ultrapassa o meu alcance; confesso-me, portanto, derrotado, vos deixando desenredar esse nó com Epistemon.

EUDOXO - Desta vez eu me encarrego disso com prazer, mas à condição de que sejais juiz de nosso debate; pois não ouso prometer que Epistemon vá se render às minhas razões. Aquele que, como ele, está cheio de opiniões e de preconceitos muito dificilmente se deixa confiar pela só luz da natureza; há muito tempo, com efeito, ele se acostumou a ceder à autoridade antes do que emprestar o ouvido à voz de sua própria razão; ele prefere interrogar os outros, sopesar o que escreveram os antigos, antes de consultar-se a si mesmo sobre o juízo que deve fazer. E, da mesma forma que, desde a infância, ele tomou por razão o que não repousava senão sobre a autoridade de seus preceptores, assim também ele agora nos oferece a sua autoridade como sendo a razão, e quer que os outros lhe paguem o mesmo tributo que outrora pagou. Terei motivos, porém, para ficar feliz, e acredito poder satisfazer plenamente às objeções que proponhais a Epistemon, caso venhais a dar vosso assentimento ao que direi e desde que vossa razão disso vos convença.

EPISTEMON - Não sou tão obstinado nem tão difícil de persuadir como vós pensais, e muito voluntariamente estou receptivo a que me satisfaçam. Além disso, por mais que eu tenha razões para desconfiar de Poliandro, vos peço apenas que coloquemos nossa contenda em suas mãos; eu vos prometo mesmo dar-me por vencido tão logo ele deposite as armas. Mas que ele tenha cuidado para não aceitar ser enganado, e para não cair no erro que ele atribui aos outros, isto é, o de tomar por uma razão convincente a estima em que ele vos tem.

EUDOXO - Se ele se apoiasse sobre um fundamento tão fraco, certamente compreenderia mal o que está em jogo, mas eu respondo desde já que ele se sairá 
bem. Basta, porém, de digressões; voltemos ao nosso assunto. Concordo convosco, Epistemon, que é preciso saber o que é a dúvida, o pensamento, a existência, antes de estar inteiramente convencido da verdade desse raciocínio: eu duvido, logo, existo; ou, o que é a mesma coisa: eu penso, logo, existo. Mas não vades imaginar que, para adquirir essas noções prévias, seja preciso violentar e torturar nosso espírito para encontrar o gênero mais próximo e a diferença essencial, e desses elementos compor uma verdadeira definição. Deixemos essa tarefa àquele que aspira ser professor ou disputar nas escolas. Qualquer um que deseja examinar as coisas por ele mesmo e julgá-las conforme as concebe não pode ser de um espírito tão limitado que não tenha o tanto de luz para ver suficientemente, todas as vezes que nelas preste atenção, o que é a dúvida, o pensamento, a existência, e para que lhe seja necessário aprender tais distinções. Além disso, há muitas coisas que tornamos mais obscuras querendo defini-las, porque, como elas são muito simples e muito claras, é-nos impossível conhecê-las e compreendê-las melhor do que por elas mesmas. Ainda mais, entre os maiores erros que se pode cometer nas ciências, é preciso contar talvez o erro daqueles que querem definir o que se deve tão somente conceber, e que não conseguem nem distinguir as coisas claras das coisas obscuras tampouco discernir o que, para ser conhecido, exige e merece ser definido do que pode ser muito bem concebido por si mesmo. Ora, entre as coisas que são de tal modo claras que as conhecemos por elas mesmas, podemos inserir a dúvida, o pensamento e a existência.

Não creio que alguma vez tenha havido pessoa tão estúpida que precisasse aprender o que é a existência antes de poder concluir e afirmar que existisse. Ocorre o mesmo com a dúvida e com o pensamento. Acrescento também que é impossível aprender essas coisas de outro modo senão por si mesmo, e de se persuadir de outra maneira senão por sua própria experiência e por essa consciência ou testemunho interior que cada homem encontra em si mesmo quando considera uma observação qualquer; de tal modo que, da mesma forma que seria inútil definir o que é o branco para tornálo compreensível a um cego, ao passo que, para conhecê-lo, é-nos suficiente abrir os olhos e ver o branco, assim também, para saber o que é a dúvida e o pensamento, basta duvidar e pensar. Isso nos ensina tudo o que podemos saber a esse respeito, e nos diz até mais do que as definições mais exatas. É verdade, portanto, que Poliandro precisou conhecer tais coisas antes de poder delas deduzir as conclusões que ele formulou. De resto, já que o elegemos por juiz, vamos questioná-lo se alguma vez ignorou o que é a dúvida, a existência, o pensamento.

POLIANDRO - Devo admitir que foi com o maior prazer que vos ouvi debater sobre uma coisa que não poderiam aprender senão comigo, e vejo com certa alegria que é preciso, ao menos nessa ocasião, reconhecer-me por vosso mestre e que reconheçais a vós mesmos como meus discípulos. É por isso que, para vos livrar do embaraço e resolver prontamente vossa dificuldade (dizemos, com efeito, que uma 
coisa é feita prontamente sempre que ela ocorre contra toda expectativa e contra toda atenção), vos asseguro que jamais duvidei do que é a dúvida, por mais que eu não tenha começado a conhecê-la ou, melhor, a refletir sobre ela, senão quando Epistemon quis colocá-la em dúvida. Mal havieis vós me mostrado o pouco de certeza que temos da existência das coisas que conhecemos com a ajuda apenas dos sentidos que comecei a duvidar dessas coisas, e isso foi suficiente para me fazer conhecer, ao mesmo tempo, tanto a minha dúvida quanto a certeza dessa dúvida. Posso então afirmar que comecei a me conhecer logo que comecei a duvidar; mas não era aos mesmos objetos que se reportavam minha dúvida e a minha certeza, pois minha dúvida se aplicava somente às coisas que existem fora de mim, e minha certeza se aplicava à minha dúvida e a mim mesmo. Eudoxo tinha razão, portanto, de dizer que há coisas que não podemos aprender senão vendo-as. Assim também, para aprender o que é a dúvida, o que é o pensamento, basta apenas cada um duvidar e pensar. O mesmo vale para a existência. É preciso saber somente o que se entende por essa palavra; e imediatamente se conhece a coisa, tanto quanto seja possível ao homem conhecê-la, e para isso não há necessidade de definições; elas obscureceriam a coisa antes do que as esclareceriam.

EPISTEMON - Já que Poliandro está contente, rendo-me igualmente e não prolongarei mais a disputa. Não vejo, contudo, que ele tenha avançado muito após termos ficado aqui por duas horas raciocinando. Tudo o que ele aprendeu com o auxílio desse belo método que tanto vos orgulha é que ele duvida, que ele pensa e que ele é uma coisa pensante. Descoberta verdadeiramente admirável! Eis aí muito discurso para bem poucas coisas. Poderíamos ter dito tudo isso em quatro palavras, e todos nós estaríamos de acordo. Quanto a mim, se eu tivesse que gastar tanto palavrório e tanto tempo para aprender uma coisa de tão pequeno interesse, eu teria dificuldade de resignar-me a isso. Nossos mestres nos dizem bem mais e são muitíssimo mais ousados; nada os detêm, eles assumem tudo para si e se pronunciam acerca de tudo; nada os desvia de seu objetivo nem os enche de espanto; o que quer que aconteça, enfim, quando se encontram muito pressionados, uma ambiguidade ou uma distinção os remove de todo embaraço. Estai certo de que o método deles será sempre preferível ao vosso, que duvida de tudo e tanto receia em dar um passo em falso que, pisoteando, não avança jamais.

EUDOXO - Nunca tive a intenção de prescrever a quem quer que seja um método que deveria ser seguido para a busca da verdade; quis somente expor aquele de que me servi, a fim de que, caso seja julgado como ruim, seja rejeitado; mas, ao contrário, caso o julguem bom e útil, que sirva aos demais também. De resto, deixo cada um inteiramente livre para admiti-lo ou rejeitá-lo. Agora, caso se venha a dizer que ele não me trouxe avanços, cabe à experiência julgá-lo, e eu estou certo contanto que continueis me emprestando vossa atenção - de que vós mesmos ireis confessar que não podemos ser tão circunspectos no estabelecimento dos princípios, 
e que, uma vez os princípios solidamente postos, poderemos estender as consequências mais além e as deduzir mais facilmente do que poderíamos ousar nos prometer. Penso também que todos os erros que ocorrem nas ciências advêm apenas do tanto de pressa com que começamos a julgar, admitindo por princípio coisas obscuras, coisas das quais não tínhamos nenhuma noção clara e distinta. $\mathrm{O}$ que prova a verdade dessa asserção é o progresso, embora pequeno, que temos feito nas ciências em que os princípios são certos e conhecidos por todos, ao passo que, por outro lado, naquelas ciências em que os princípios são obscuros e incertos, os que pretendem ser sinceros são forçados a admitir que, depois de terem gasto muito tempo e de terem lido muitos volumes, deveriam reconhecer não saberem nada e não terem aprendido nada. Não vos surpreendais, portanto, meu querido Epistemon, se, querendo conduzir Poliandro por um caminho mais seguro do que aquele que me foi ensinado, eu seja severo a ponto de só reter por verdadeiro aquilo de que tenho uma certeza igual à de que eu sou, de que eu existo, de que eu penso e de que sou uma coisa pensante.

EPISTEMON - Vós me pareceis semelhante àqueles saltadores que sempre caem sobre seus próprios pés; vós retornais sempre ao vosso princípio; se continuardes desse modo, não ireis nem longe nem depressa. Como, com efeito, encontraremos a qualquer tempo verdades das quais podemos estar tão certos quanto nossa existência?

EUDOXO - Isso não é tão difícil quanto acreditais, uma vez que todas as verdades se sucedem umas às outras e estão unidas por um mesmo laço. Todo o segredo consiste em começar pelas primeiras e mais simples, e em elevar-se em seguida pouco a pouco e como que por degraus até as verdades mais distantes e mais compostas. Ora, quem duvidará de que o que pus como princípio não seja a primeira de todas as coisas que podemos conhecer com algum método? É seguro, com efeito, que não podemos duvidar dela, mesmo quando duvidamos da verdade de tudo o que o universo contém. Então, para que estejamos certos de que começamos bem, é preciso, para não nos desgarrarmos na sequência, ter o cuidado, e é o que fizemos, de não admitir como verdade o que está sujeito à menor dúvida. Para este fim, é necessário, em minha opinião, deixar Poliandro que fale só ele, pois, como ele não segue nenhum outro mestre senão o senso comum, e como sua razão não se alterou por nenhum prejuízo, é quase impossível que se engane, ou, ao menos, ele se aperceberá facilmente e voltará sem dificuldade para o caminho reto.

EPISTEMON - Escutemo-lo, pois, falar, e deixemo-lo expor as coisas que diz estarem contidas em vosso princípio.

POLIANDRO - Há tantas coisas contidas na ideia que apresenta um ser pensante que precisaríamos de dias inteiros para desenvolvê-las. Então, para o momento, trataremos apenas das principais e daquelas que servem para tornar mais clara a 
noção desse ser, e que a distinguem de tudo o que não tem relação com ele. Eu entendo por ser pensante...

(O texto termina abruptamente aqui).

\section{Referências}

BORBA, Maíra de Souza. A Recherche de la Vérité de Descartes e as Objeções feitas às Meditações Metafísicas: para uma abordagem sistemática do problema da datação. 2015. Tese (Doutorado em Filosofia) - Faculdade de Filosofia e Ciências Humanas, Universidade Federal de Minas Gerais, Belo Horizonte.

DESCARTES, R. Euvres Choisies de Descartes.Paris, Garnier Frères, 1865. Disponível em: <https://archive.org/details/oeuvreschoisiesdoodesc>. Acesso em: 15 mar. 2018.

.CEuvres de Descartes. Edição de Charles Adam e Paul Tannery (AT). Paris, Vrin, 1996. vol. X.

. Euvres Philosophiques de Descartes. Edição de Ferdinand Alquié. Paris, Garnier, 1988-89. vol. II.

Submissão: 23.03.2018 / Aceite: 20.06.2018. 